\title{
G schem \\ Effect of Educating Healthy Women About Breast Cancer on Their Fear of Breast Cancer and Breast Cancer Worry
}

\section{Aliakbar Nejatisafa}

Tehran University of Medical Sciences

\section{Yas Eskandari}

University of Tehran

\section{Ladan Hosseini}

Tehran University of Medical Sciences

\section{Sepehr Boroumand Sani}

Tehran University of Medical Sciences

\section{Amirhossein Eskandari}

Ministry of health and Medical Education

\section{Forouzandeh Jannat}

Tehran University of Medical Sciences

\section{Marzieh Orouji}

Tehran University of Medical Sciences

\section{Donya Goodarzi}

Tehran University of Medical Sciences

Sadaf Alipour ( $\square$ sadafalipour@yahoo.com )

Tehran University of Medical Sciences

\section{Research Article}

Keywords: Breast Cancer, Lerman Score, Champion Score, HADS, Fear, Worry, Knowledge, Teaching Posted Date: September 13th, 2021

DOl: https://doi.org/10.21203/rs.3.rs-821017/v1

License: (c) (i) This work is licensed under a Creative Commons Attribution 4.0 International License. Read Full License 


\section{Abstract}

Background Breast cancer (BC) is the most common cancer among females worldwide and prognosis depends on early diagnosis; however women seldom seek medical attention on time. Two of the important reasons for this delay are $\mathrm{BC}$ worry (BCW) and fear (BCF). We aimed to assess whether educating healthy women about BC could affect their BCF and BCW.

Methods Participants were women above 18 years who visited the Breast Clinic who had a normal or benign breast assessment and were not suffering from any psychological disorder. They filled a survey including items of the hospital anxiety and depression scale (HADS), Lerman BCW scale and Champion BCF scale before and after the intervention. In the course of the study, 20 short educational videos about $\mathrm{BC}$ were sent to all of them by WhatsApp.

Results The mean age of the 104 participants was 38.37 years. HADS scores showed a fairly good general psychological health of the participants before and after the intervention. The mean BCW and BCF score decreased significantly after vs. before the intervention.

Conclusions Our study showed that educating healthy women about BC can effectively reduce BCF and $\mathrm{BCW}$. We suggest that similar studies follow the participants in order to assess the effect on their healthseeking behaviour about $\mathrm{BC}$ in the long term.

\section{Background}

Breast cancer (BC) is the most common cancer among females and constitutes the second leading cause of cancer death in women globally [1]. Types and extent of treatments, tumor response, survival and quality of life of the patients depends on the inherent characteristics of the disease, like tumor grade; but also on the stage at diagnosis $[2,3]$. Therefore, early diagnosis and management of $\mathrm{BC}$ plays a key role in its overall prognosis and deeply affects the forthcoming years of life of the patient. Also, detection of precancerous breast lesions $[4,5]$, or recognition of $B C$ risk factors including genetic predisposition in women can ease prevention or timely diagnosis of the cancer [6]. However, all these can only be achieved in a setting where the patient is seen before any symptom (as opportunistic or organized BC screening) or at the first probable presentation. Unfortunately, very frequently, women seek medical attention with a significant delay; which affects the clinical picture negatively $[7,8]$.

Two of the main obstacles against seeking medical attention for breast conditions are the concerns women have about the possible results of the examinations, and a sense of fear of the cancer $[9,10,11$, 12]. In other words, $\mathrm{BC}$ worry (BCW) and $\mathrm{BC}$ fear (BCF) interfere with appropriate care demand.

Considering these facts, we pondered whether a higher knowledge of $\mathrm{BC}$ would soften $\mathrm{BCW}$ and $\mathrm{BCF}$, or increase the concerns and fears. Therefore, we carried out the present study to investigate the effect of educating healthy women about BC on BCF and BCW. 


\section{Methods}

\section{Study design and participants}

This study was carried out in the Breast Clinic of Arash Women's Hospital, affiliated to Tehran University of Medical Sciences (TUMS) from first October 2020 to first April 2021. It was approved by the Institutional Research Board (Proposal Code: 99-1-259-47062) and the Ethics Committee (Approval ID: IR.TUMS.IKHC.REC.1399.113) of TUMS, Tehran, Iran. All participating women virtually signed the research informed consent before entering the study.

\subsection{Study Outcomes}

Our primary outcome was the amount of change in BCF and BCW before and after the intervention as measured by the research questionnaires. The secondary outcome was the association between the previous breast-related medical history of the patients and the amount of the basic and post-intervention BCF and BCW.

\subsection{Inclusion and Exclusion criteria, Sample size calculation}

As per the initial design of the research, participants were planned to be selected among the women attending the Breast Clinic of the hospital for screening purpose or for benign breast complaints. However, due to the restrictions created by the COVID-19 pandemic and the conversion of physical presence of patients to virtual modes of visits [13], the plans and the inclusion criteria changed relevantly. Therefore, participants were chosen among women who had attended the Breast Clinic during the last two years and had their phone numbers recorded in their files. Inclusion criteria consisted of age above 18 years, willingness to participate, a normal previous breast history and breast exam, and a normal or benign last breast imaging. Exclusion criteria comprised history of breast or any other cancer, new breast complaints, first-degree family history of BC, history of psychological disease, illiteracy, and inability to use virtual platforms.

We calculated the sample size based on the presumption of at least $3 \%$ change in BCF score after the intervention, considering a power of $80 \%$ and a confidence interval of $95 \%$. Thus, a sample size of 102 women was estimated as appropriate.

\subsection{Interventions, measurements, and tests}

Records of the probably eligible women were picked out from the clinic files by the surgeon of the Breast Clinic. A trained staff called them, explained the study, and asked questions regarding the inclusion and exclusion criteria. Then, cases qualified for the study were enrolled after giving their virtual consent to participate.

First, all participants filled a survey which consisted of 34 items, including 11 queries about their general characteristics and medical histories, and 23 questions investigating their general psychological health, 
$\mathrm{BCW}$ and BCF. Among these 23 questions, the first two consisted of two of the three questions of the Lerman BC Worry Scale [14]. This scale [14] consists of three questions, inquiring about the rate of worrying, the effect on the patient functioning, and the effect on their mood. Lee et al [15] have adapted the first two in order to assess BCW in their cases, and we used these two questions accordingly.

The next seven questions were the Champion BC fear scale. This standard validated scale consists of eight questions [16], however in the Farsi translation the two last questions have been merged (resulting in seven questions) after undergoing validation and reliability tests by Moshki et al [17]. The last fourteen questions consisted of the hospital anxiety and depression scale (HADS) [18]. The Farsi version of HADS has previously been validated by Montazeri et al [19]. The first seven questions investigate the anxiety, and the following seven the depression of the patient. Questionnaires were made available to the patients via Google forms (https://www.google.com/forms/about/) which enabled them to answer the tests anonymously. Patients were only recognized by a number which was assigned by the link.

In the following steps, a series of messages consisting of twenty short videos, including animated texts and images about $\mathrm{BC}$ definition, clinical presentation, diagnosis, treatment, impact of early diagnosis on disease management, and follow-up were sent to all participants. The content and format of the messages had been prepared earlier for another study (Boroumand Sani et al. Forthcoming) in seven steps by a team consisting of two breast surgeons, a general surgeon, a gynecologist, an expert in validation of short-courses for medical knowledge and skills, three breast care nurses, two oncologic nurses, two general nurses, a medical student, a post-graduate student of medical education, two school teachers, two unrelated (non-medical or paramedical) students, and three housewives. To summarize the process), the steps for providing an appropriate content consisted of drafting the topics and details in a popular language, correction for missing topics and simplicity of language in two phases, adding people questions gathered through a preliminary study (Boroumand Sani et al. Forthcoming), drawing cartoon pictures, last two rechecks, and finalizing. Then, the content was converted to short interesting videos. In the previous study, the messages had been sent to a group of healthy women, and the rate of learning as well as the satisfaction of the participants had been assessed (Alipour et al. Forthcoming); both variables had shown a high level in the analysis.

In the present study, the messages were sent one by one on a daily basis by the WhatsApp mobile application privately to each participant, in order to make sure they received and opened every message. Around one month after sending the last film, another survey was filled by the participants via the same method, containing only the 23 questions of HADS, Lerman BCW scale and Champion BCF scale.

\subsection{Statistical Analysis Methods}

The statistical analyses were performed using IBM SPSS 24 (IBM Corp. Released in 2016. IBM SPSS Statistics for Windows, Version 24.0. Armonk, NY: IBM Corp). Data are presented as mean \pm standard deviation for continuous variables and number with percentages for categorical variables. 
The BCF score was calculated from the 7 questions of the Champion scale and the BCW score from the two questions of the Lerman scale. Depression and anxiety were estimated based on the seven first and second question of HADS, respectively; and the total HADS score was used as the general psychological health score.

For investigating the alterations in general psychological health, BCF and BCW, the Kolmogorov-Smirnov test did not confirm normal distribution. Therefore, analysis of these variables was performed by using the Wilcoxon test. The association of BCF and BCW changes with patient features was analyzed by using the Spearman's correlation test for continuous variables, and Mann-Whitney $U$ test or Kruskal-Wallis for the nominal variables.

\section{Results}

One-hundred and four women were entered in the study; all except one followed the study till the end. Among the 103 patients, one did not fill out the HADS questions, and two missed the second half (depression section) of HADS.

The mean age of the participants was $38.37( \pm 9.14)$ years. Patient features including level of education, history of benign breast disease or breast surgery for benign lesions, and consumption of oral contraceptives (OCP) or hormone replacement therapy (HRT) in all participants are demonstrated in Table 1.

Table 1

Level of education and past related history of all participants

\begin{tabular}{|ll|}
\hline Variable & Number (percentage) \\
\hline Education & \\
\hline High school & $53(60.6)$ \\
\hline Academic & $41(39.4)$ \\
\hline Benign breast disease & $42(40.4)$ \\
\hline OCP consumption & $28(26.9)$ \\
\hline Hormone replacement therapy & $8(7.8)$ \\
\hline
\end{tabular}

The anxiety and depression scores according to HADS, and the total score are demonstrated in Table 2. These scores show that the general psychological health of the participants at the point of entry to the study was fairly good, and did not change significantly after the intervention. 
Table 2

HADS-Anxiety Score, depression scores and total scores of all participants

\begin{tabular}{|lllllll|}
\hline & \multicolumn{2}{l}{$\begin{array}{l}\text { HADS-Anxiety } \\
\text { Score }\end{array}$} & \multicolumn{2}{l}{$\begin{array}{l}\text { HADS-Depression } \\
\text { Score }\end{array}$} & \multicolumn{2}{l|}{ HADS Total Score } \\
\hline $\begin{array}{l}\text { Before or after the } \\
\text { intervention }\end{array}$ & Before & After & Before & After & Before & After \\
\hline Number of participants & 104 & 102 & 104 & 101 & 104 & 100 \\
\hline Mean & 9.21 & 9.01 & 8.93 & 9.05 & 18.14 & 18.04 \\
\hline Standard. Deviation & 2.41 & 2.21 & 2.09 & 1.97 & 3.03 & 2.85 \\
\hline p-value & 0.441 & & 0.612 & & 0.637 & \\
\hline
\end{tabular}

The mean BCW score, according to the two questions of the Lerman scale, was $7.95 \pm 1.67$ before the intervention. The mean changed to $4.02 \pm 1.44$ after the intervention, which showed a statistically significant decrease in the Wilcoxon test $(p<0.001)$.

The mean BCF score was $22.29 \pm 4.09$ at the beginning of the study, and declined to $21.43 \pm 4.99$ after the education course. This decrease was statistically significant $(p=0.046)$ according to the Wilcoxon test.

In the next step, we explored the association of the changes in BCW and BCF of patients with patient characteristics and history. There was no significant association between BCW and BCF and age (BCW: $p$ $=0.981$, BCF: $p=0.959$ ); level of education (BCW: $p=0.771, B C F: p=0.166$ ); benign breast disorders (BCW: $p=0.344, B C W: p=0.578) ; O C P$ use (BCW: $p=0.836, B C F: p=0.258)$ and HRT (BCW: $p=0.12, B C F$ : $p=0.80)$.

\section{Discussion}

In this study we evaluated the effect of providing healthy women with appropriate educational material about BC on their fear and worry about the disease, and found that this approach could lessen BCW and BCF.

While timely diagnosis of $\mathrm{BC}$ is of utmost importance in the prognosis of the disease, several factors deter this crucial issue. Considering the implication of the subject, some studies have addressed it by questioning healthy women or patients about the causes for their delays.

By using a structured questionnaire to detect rate of practice of breast self-examination in 261 participants, Parsa et al [20] defined fear from detection of a mass as the reason for avoiding the exam in only $17 \%$ of cases. Correspondingly, in a large survey recently held by Gümüştakim et al [21] on 643 women attending 18 Family Health Centers throughout Turkey, fear from the results was the cause for $15 \%$ of evasions from screening. 
However, Consedine et al [9] explored the emotional factors that affected the rate of undergoing mammography in 1634 African-American women from 6 different ethnicities, and found a significant negative relationship with BCW. Also, Fouladi et al [10] investigated the topic in 380 women who attended health centers, and detected that around $76 \%$ of the participants avoided mammography in fear of finding a possible malignant tumor. Accordingly and through in-depth interviews with 22 healthy women based on the Health Belief Model, Noori and Shouten [22] showed that while the participants believed on the benefits of mammography, fear was one of the main barriers for performing it; this factor also hindered them from performing breast self-examination. Interestingly, Asmar et al [12] showed that while fear from hearing bad news about their breasts prevented women from undergoing $B C$ screening; a higher knowledge of the disease reduced this effect. Likewise, subsequent to the detection of BCF as one of the main themes that induced delays in diagnosis, Cipora et al [11] emphasized that educating women about the importance of early detection of $\mathrm{BC}$ and its impact on successful management of the disease should be carried out in order to improve the situation.

Despite the fact that BCF and BCW have been recognized as a main cause of late BC diagnosis in these studies, and while providing knowledge about $\mathrm{BC}$ and the importance of early detection has been proposed as a solution for this matter, no study has evaluated the actual effect of these instructions on $\mathrm{BCF}$ and BCW. On the other hand, there is also the theoretical possibility that having a higher knowledge about a malignant disease could also induce fear and worry. Therefore, the actual association of providing knowledge about the disease and related emotional consequences need to be addressed in studies dedicated to this specific question; this has been achieved in our study.

The effect of education on fear has been investigated in other medical conditions. For example, it has been shown that antenatal education of pregnant women could diminish the fear of childbirth $[23,24]$. Also, courses of death education had caused decrements in fear of death in students $[25,26]$. On the other hand, studies have looked at the effect of psychoeducation in the fear of BC recurrence and cancer distress in survivors of the disease. Psychoeducation generally comprises both educational points about $\mathrm{BC}$ and psychological support of the patients and their family. In a study by Stanton et al [27] on around 400 patients, psychoeducation neither decreased depressive symptoms nor distress. However, in a multicenter study carried out by Weis et al [28] on 50 patients with BC, psychoeducation induced a significant drop in fear of progression and fear of recurrence of BC.

In our study, the effect of education on BCF and BCW was investigated by a very practical, reproducible method. The instruction material was prepared by a reliable, pertinent team; and consisted of easy-tounderstand, attractive messages that had shown effective regarding their scientific content and instructive effect, and satisfactory to most patients in a previous study (Boroumand Sani et al. Forthcoming). BCF and worry were assessed by standard validated tests $[14,15,16,17]$, and the general psychological health of all participants was accredited before and after the intervention by a validated test (HADS). This precise design has shown that giving useful information about BC can effectively reduce the fear and worries of healthy women about the disease. 
Our study had some limitations. First, it was held in a single center. Although the population who attend the Clinic in our hospital is quite diverse regarding their socioeconomic background, the involvement of several centers and including a more diverse population could further confirm the consistency of the results. Also, we did not explore the effect of our intervention on patient's behaviour regarding BC screening, which is rather the ultimate goal.

\section{Conclusion}

Our study showed that educating healthy women about BC can reduce their fear and worry about the disease. We suggest that similar studies be performed in a multi-centric design, by following the women for a reasonable time after the instructions in order to assess the effect on their health-seeking behaviour about BC.

\section{Abbreviations}

$\mathrm{BC}=$ Breast cancer, $\mathrm{BCW}=$ breast cancer worry, $\mathrm{BCF}=$ breast cancer fear, HADS= hospital anxiety and depression scale, TUMS= Tehran University of Medical Sciences, $\mathrm{BCN}=$ breast care nurses

\section{Declarations}

\section{Ethics approval and consent to participate:}

All methods were performed in accordance with the guidelines and regulations of the Ethics Committee of Tehran University of Medical Sciences, Tehran, Iran, and in accordance with the Declaration of Helsinki; the study Approval ID in the Committee is IR.TUMS.IKHC.REC.1399.113. All participating women virtually signed the research informed consent before entering the study.

\section{Consent for publication:}

Not applicable

\section{Availability of data and materials:}

Not applicable

\section{Competing interests:}

Not applicable

\section{Funding:}

Not applicable

\section{Authors' contributions:}


AN: Methodology, Supervision, Data curation, Reviewing and Editing; YE: Conceptualization, WritingReviewing and Editing; LH: Methodology, SBS: Visualization, Investigation; AE: Methodology, Supervision; FJ: Supervision, MO: Visualization, Investigation; DG: Visualization, Investigation; SA: Conceptualization, Methodology, Writing- Original draft preparation, Project administration.

\section{Acknowledgements:}

We would like to acknowledge Dr. Azin Saberi and Mrs Matina Noori for their collaboration in recruitment of participants.

\section{Declarations of interest:}

none

\section{References}

1. Bray F, Ferlay J, Soerjomataram I, Siegel RL, Torre LA, Jemal A. Global cancer statistics 2018: GLOBOCAN estimates of incidence and mortality worldwide for 36 cancers in 185 countries. CA Cancer Journal for Clinicians. 2018; 68:394-424.

2. Iqbal J, Ginsburg O, Rochon PA, Sun P, Narod SA. Differences in breast cancer stage at diagnosis and cancer-specific survival by race and ethnicity in the United States. Jama. 2015; 313:165-73.

3. Sant M, Allemani C, Capocaccia R, Hakulinen T, Aareleid T, Coebergh JW, Coleman MP, Grosclaude P, Martinez C, Bell J, Youngson J. Stage at diagnosis is a key explanation of differences in breast cancer survival across Europe. International journal of cancer. 2003;106:416-22.

4. Hashemi E, Haghighat S, Olfatbakhsh A, Beheshtian T, Sari F, Sajadian A. Upgrading Rate of Precancerous Breast Lesions in Pathology and Related Clinicoradiological Characteristics. Iranian Quarterly Journal of Breast Disease. 2018;10:18-28.

5. Thomas ET, Del Mar C, Glasziou P, Wright G, Barratt A, Bell KJ. Prevalence of incidental breast cancer and precursor lesions in autopsy studies: a systematic review and meta-analysis. BMC cancer. 2017;17:808.

6. Sun YS, Zhao Z, Yang ZN, Xu F, Lu HJ, Zhu ZY, Shi W, Jiang J, Yao PP, Zhu HP. Risk factors and preventions of breast cancer. International journal of biological sciences. 2017;13:1387.

7. Jassem J, Ozmen V, Bacanu F, Drobniene M, Eglitis J, Lakshmaiah KC, Kahan Z, Mardiak J, Pieńkowski T, Semiglazova T, Stamatovic L. Delays in diagnosis and treatment of breast cancer: a multinational analysis. The European Journal of Public Health. 2014;24:761-7

8. Rivera-Franco MM, Leon-Rodriguez E. Delays in breast cancer detection and treatment in developing countries. Breast cancer: basic and clinical research. 2018; 12:1-5.

9. Consedine NS, Magai C, Neugut Al. The contribution of emotional characteristics to breast cancer screening among women from six ethnic groups. Preventive Medicine. 2004;38:64-77. 
10. Fouladi N, Pourfarzi F, Mazaheri E, Asl HA, Rezaie M, Amani F, Nejad MR. Beliefs and behaviors of breast cancer screening in women referring to health care centers in northwest Iran according to the champion health belief model scale. Asian Pacific Journal of Cancer Prevention. 2013;14:6857-62.

11. Cipora EL, Konieczny M, Czerw AL, Mikos M, Budzik MP, Deptała A, Badowska-Kozakiewicz AM. Causes of delays in breast cancer diagnosis in Poland. Polski merkuriusz lekarski: organ Polskiego Towarzystwa Lekarskiego. 2019;47:85-90.

12. El Asmar M, Bechnak A, Fares J, Al Oweini D, Alrazim A, El Achkar A, Tamim H. Knowledge, attitudes and practices regarding breast cancer amongst Lebanese females in Beirut. Asian Pacific journal of cancer prevention: APJCP. 2018;19:625.

13. Alipour S, Moini A, Orouji M, Saberi A, Motamedi M, Eskandari A. COVID-19 Outbreak and Consequent Delays in Schedules of the Breast Clinic: Effects on Patients' Breast and Emotional Symptoms. European Journal of Breast Health. 2020;16:250.

14. Lerman C, Trock B, Rimer BK, Jepson C, Brody D, Boyce A. Psychological side effects of breast cancer screening. Health psychology. 1991;10:259.

15. Lee JM, Lowry KP, Chubiz JE, Swan JS, Motazedi T, Halpern EF, Tosteson AN, Gazelle GS, Donelan K. Breast cancer risk, worry, and anxiety: Effect on patient perceptions of false-positive screening results. The Breast. 2020; 50:104-12.

16. Champion VL, Skinner CS, Menon U, Rawl S, Giesler RB, Monahan P, Daggy J. A breast cancer fear scale: psychometric development. Journal of health psychology. 2004;9:753-62.

17. Moshki M, Shahgheibi S, Taymoori P, Moradi A, Roshani D, Holt CL. Psychometric properties of the mammography self-efficacy and fear of breast cancer scales in Iranian women. BMC public health. 2017; 17:534.

18. Zigmond AS, Snaith RP. The hospital anxiety and depression scale. Acta psychiatrica scandinavica. 1983;67:361-70.

19. Montazeri A, Vahdaninia M, Ebrahimi M, Jarvandi S. The Hospital Anxiety and Depression Scale (HADS): translation and validation study of the Iranian version. Health and quality of life outcomes. 2003;1:1-5.

20. Parsa P, Kandiah M. Breast cancer knowledge, perception and breast self-examination practices among Iranian women. Int Med J. 2005;4:17-24.

21. Gümüştakim RŞ, Akbaba Ö, Bilgili P, Çevik M, Doğaner A, Coşkun E, Akdeniz M, Saper SH. Assessment of Knowledge and Attitudes of Patients About Cancer Screenings in Primary Care. Journal of Cancer Education. 2019;11:1-1.

22. Noori S, Schouten BC. Perceptions of Iranian women regarding breast cancer screening behaviour. Eastern Mediterranean Health Journal. 2018;24:1165-71.

23. İsbir GG, Inci F, Önal H, Yıldız PD. The effects of antenatal education on fear of childbirth, maternal self-efficacy and post-traumatic stress disorder (PTSD) symptoms following childbirth: an experimental study. Applied Nursing Research. 2016;32:227-32. 
24. Serçekuş P, Başkale H. Effects of antenatal education on fear of childbirth, maternal self-efficacy and parental attachment. Midwifery. 2016;34:166-72.

25. Testoni I, Ronconi L, Cupit IN, Nodari E, Bormolini G, Ghinassi A, Messeri D, Cordioli C, Zamperini A. The effect of death education on fear of death amongst Italian adolescents: A nonrandomized controlled study. Death studies. 2020; 44:-188.

26. McClatchey IS, King S. The impact of death education on fear of death and death anxiety among human services students. OMEGA-Journal of death and dying. 2015;71:343-61.

27. Stanton AL, Ganz PA, Kwan L, Meyerowitz BE, Bower JE, Krupnick JL, Rowland JH, Leedham B, Belin TR. Outcomes from the Moving Beyond Cancer psychoeducational, randomized, controlled trial with breast cancer patients. Journal of Clinical Oncology. 2005;23:6009-18.

28. Weis JB, Gschwendtner K, Giesler JM, Adams L, Wirtz MA. Psychoeducational group intervention for breast cancer survivors: a non-randomized multi-center pilot study. Supportive Care in Cancer. 2020;28:3033-40. 